\title{
Degradation due to ageing in extraction steam piping of a nuclear power plant
}

\author{
Owais Ahmed Waseem 1, 2, Waqas Ahmed Waseem ${ }^{3}$, Mahmood Khan ${ }^{4}$, Anwar Ul Hasson Syed 2, * \\ ${ }^{1}$ Nuclear Fuel Materials Laboratory, Nuclear and Quantum Engineering, Korea Advanced Institute of Science and Technology, \\ Daejeon, Republic of Korea \\ ${ }^{2}$ Karachi Institute of Power Engineering, Karachi, Pakistan \\ ${ }^{3}$ University of Karachi, Karachi, Pakistan \\ ${ }^{4}$ National Center for Non-Destructive Testing, Islamabad, Pakistan
}

\section{A R T I C LE IN F O}

Article history:

Received 27 May 2016

Received in revised form

26 July 2016

Accepted 26 July 2016

Keywords:

Aging

Steel

Power plant

Microstructures

Corrosion

\begin{abstract}
A B S T R A C T
Ageing assessment of extraction steam piping, which was limited to wall loss and corrosion, has been extended to microstructural degradation in this paper. Metallography, radiography, ultrasonic thickness and hardness measurements have been carried out for examining the virgin and twelve years old Seamless Carbon Steel SA 106B pipe in this study. In addition to commonly observed degradation mechanisms i.e. pitting and wall thinning, microstructural degradation has also been observed. The transformation of bands of pearlite and ferrite phases, present in virgin microstructure, into uniformly distributed pearlite and irregularly distribute graphite nodules have been observed due to ageing. The depletion of pearlite phase from $40 \%$ to $25 \%$ and consequent reduction in hardness up to $20.4 \%$ maximum has been observed. The more reduction in hardness of internal surface has been observed as it comes in direct contact with steam. Due to microstructural degradation with simultaneous pitting, wall thinning and reduction in mechanical properties, frequent inspection has been suggested.
\end{abstract}

(C) 2016 The Authors. Published by IASE. This is an open access article under the CC BY-NC-ND license (http://creativecommons.org/licenses/by-nc-nd/4.0/).

\section{Introduction}

Industrialization have prompted the world to get more economic and reliable source of power i.e. Nuclear Power Plants. Currently installed nuclear power plants have been in operation for decades. The specific design life of older nuclear power plants was based only on fatigue life calculation, whereas age related material degradation was ignored (IAEA Nuclear Energy Series, 2009). The materials in nuclear power plants endure hard conditions (Umer et al., 2016; Waseem and Ryu, 2016) and degrade as a result of creep, corrosion, phase changes and emerging of micro-defects. The degraded material can initiate any failure by lowering mechanical properties (Ivanova et al., 2012). Carbon steel SA $106 \mathrm{~B}$ is extensively utilized in high temperature piping of nuclear power plants. Such as seamless pipes of SA 106B are used in main steam and feed water systems. Steam outlet nozzle and condenser structure is also fabricated from the same steel grade

\footnotetext{
* Corresponding Author.

Email Address: anwar.ul.hasson@paec.gov.pk (A. H. Syed) http://dx.doi.org/10.21833/ijaas.2016.07.012

2313-626X/@ 2016 The Authors. Published by IASE.

This is an open access article under the CC BY-NC-ND license

(http://creativecommons.org/licenses/by-nc-nd/4.0/)
}

(Hänninen, 2009). It is a plain carbon steel; its structure is composed of pearlite phase in ferrite matrix. Extended exposure to high temperature and pressure conditions causes degradation in this steel, consequently threatens the safe operation by reducing strength (Mansoor and Ejaz, 2009). Replacement of such material is not considered feasible, therefore assessment of age related degradation becomes essential (Furtado and May, 2004). Material ageing has been a critical issue therefore much research work has been done regarding material ageing assessment of critical components of the nuclear power plants such as reactor pressure vessel, pressure tubes, steam generators, pressurizer, main steam piping and pipe line corrosion etc. Ageing assessment of piping has been a topic of particular interest for researchers, various studies have been published such as Ossai et al. (2016) observed increasing degradation due to prolong service of pipelines (Ossai et al., 2016), Bai et al. (2016) observed negligible effect of solution treatment on degradation of austenite steel used in piping of power plants (Bai et al., 2016) and Deng et al. (2009) found the effect of microstructure on ageing (Deng et al., 2009). To the best of our knowledge, the ageing analysis of piping is still limited to loss of material, general corrosion, crevice and pitting corrosion and wall thinning (U.S.NRC, 
2009), but this paper extends this very important to microstructural degradation.

\section{Materials and methods}

The nuclear power plant under study has been in operation for 40 years. The pipe samples of extraction steam passage way were taken, which had been carrying steam from high pressure turbine to deaerator for twelve years. The location, from where pipe samples were obtained, is shown by a red arrow in Fig. 1.

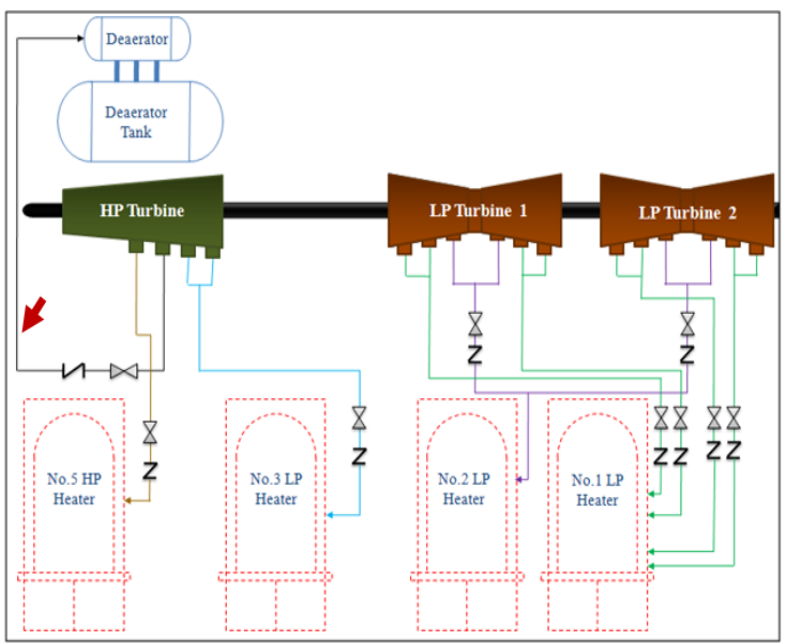

Fig. 1: Schematic diagram of extraction steam piping system

The ageing effects on extraction steam piping's material were investigated. The test sample (i.e. aged pipe of carbon steel SA 106B) having $21.34 \mathrm{~mm}$ outside diameter (OD) and $2.76 \mathrm{~mm}$ thickness was cut and subjected to thorough examination. A virgin pipe of same size, type and material was also subjected to the same analytical protocol for comparison of results. Metallographic examination was carried out using metallurgical microscope. Samples were prepared for metallography according to standard procedure as given in ASTM E3. Image software was used to determine the content of different phases. Radiographic examinations were carried out by Smart $225 \mathrm{KV}$ X-ray machine according to ASME SEC-V guideline. Samples were exposed for 60 seconds. The image quality indicator (IQI) having $0.25 \mathrm{~mm}$ diameter was used as per ASTM 1A-6. Ultrasonic tests were performed to measure the reduction in thickness due to erosion according to ASTM E-18. DM4 DL ultrasonic thickness gauge was utilized. Hardness measurement was done in Rockwell Hardness Scale B according to ASTM E-18. Hardened steel sphere of $1 / 16$ " diameter was forced in the specimen surface by applying $100 \mathrm{Kg}$ load using ZHR Rockwell Hardness Tester; $10 \mathrm{Kg}$ minor load was also applied initially to hold the sample firmly by an initial penetration and to enhance the accuracy of results.

\section{Results and discussion}

Aged, (c) Cut-off View of External Surface of Aged Pipe Showing Corrosion Pits at $100 \mathrm{X}$ magnification.

Visual examination shows no disturbance in uniformity of virgin pipe, See Fig. 2(a). Whereas, aged pipe surface as shown in Fig. 2(b) shows corrosion, as it has been in sea shore environment which is highly corrosive. Corrosion has the potential to reduce a design life of the component by premature degradation (Ginzel, 2002). Examination of corroded surface under metallurgical microscope, as shown in Fig. 2(c), reveals formation of corrosion pits, maximum depth of pit is $0.07 \mathrm{~mm}$, which causes non-uniform reduction in thickness and reduces the ultimate strength of the material (Sidharth, 2009).

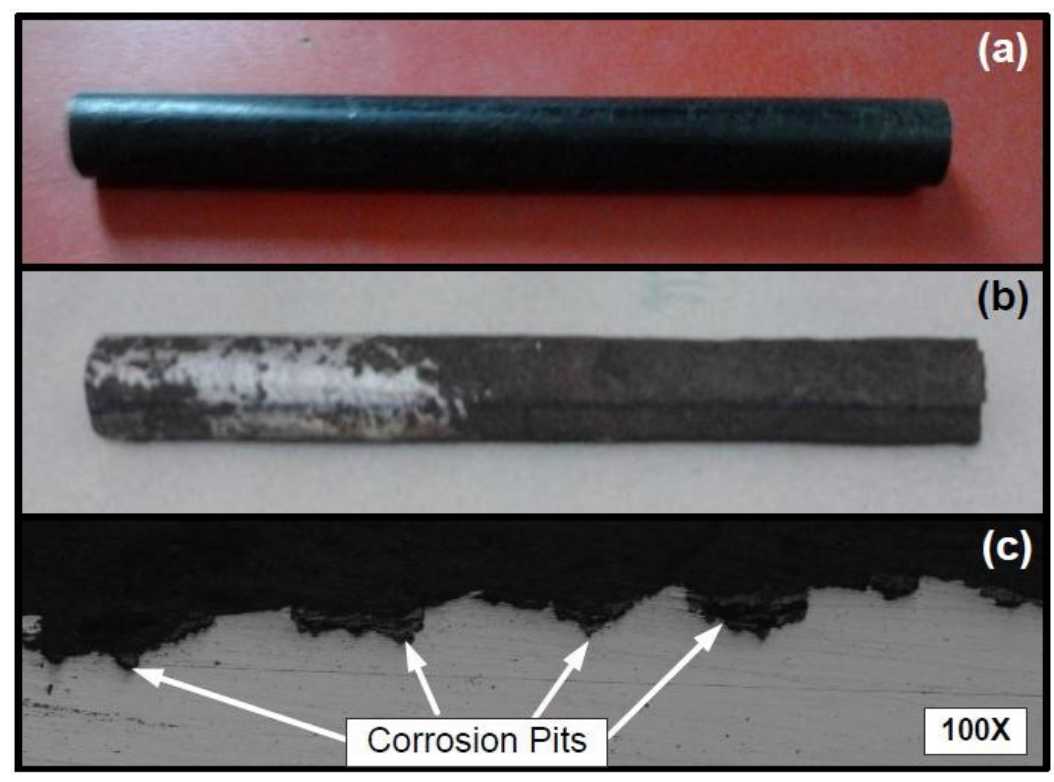

Fig. 2: SA 106B seamless pipe, (a) virgin, (b)

Radiographic examination of virgin pipe exhibits no sign of erosion, as shown in Fig. 3(a). Whereas material removal is evident on the internal surface of aged pipe, see Fig. 3(b) which shows mechanical 
rubbing of steam on internal surface of service exposed pipe (Callister and Rethwisch, 2007). Steam is supplied from middle stage extraction of high pressure turbine to deaerator at 15 psi pressure and $250{ }^{\circ} \mathrm{F}$ temperature conditions.

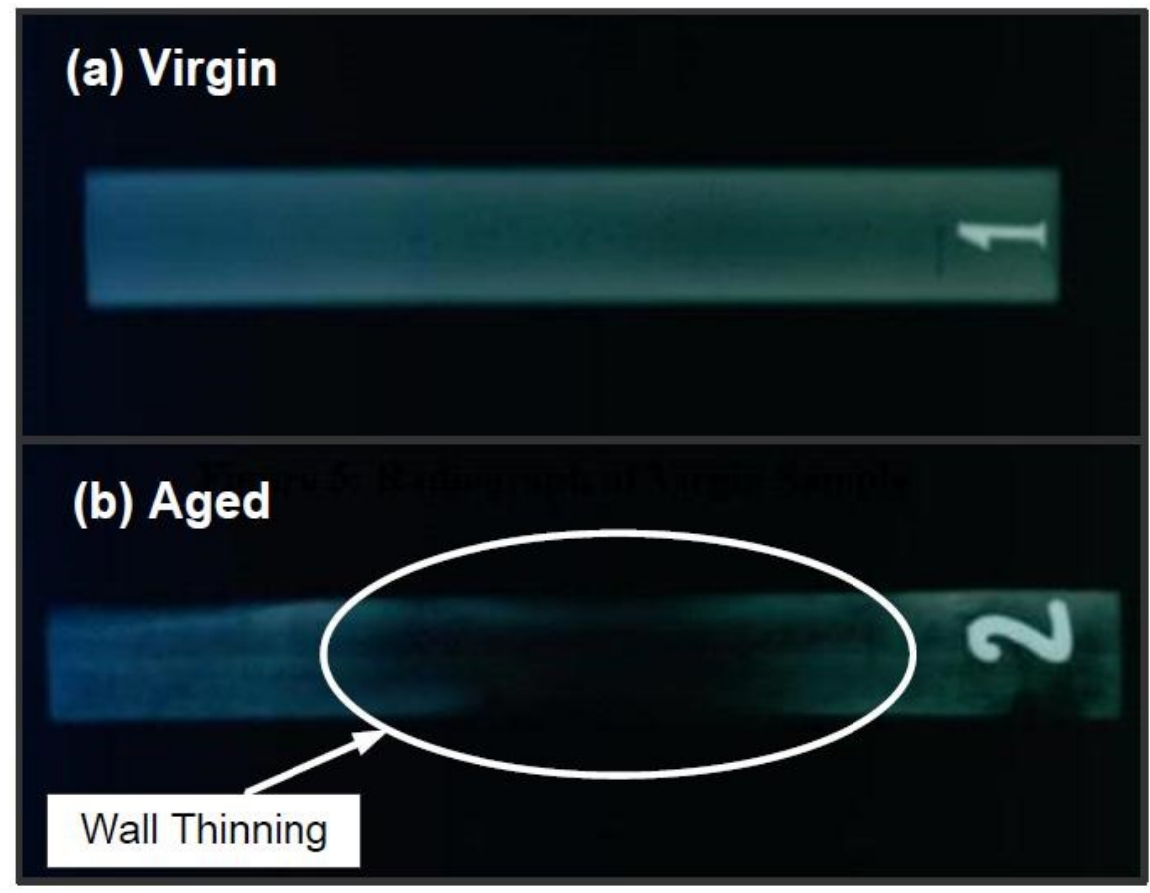

Fig. 3: Radiographs of (a) virgin pipe and (b) aged pipe

Ultrasonic testing has been performed to determine the intensity of wall thinning due to material removal. On average; $10.46 \%$ reduction in thickness is observed from $2.77 \mathrm{~mm}$ to $2.48 \mathrm{~mm}$ due to 12 years of service. Consequently, the average hoop stress which acts in radial direction because of the pressure inside the pipe and depends upon thickness of pipe, increases up to $13 \%$ from 50.29 psi to $56.87 \mathrm{psi}$. As the pipe degrades and thickness reduces, the possibility of pipe failure increases due to increase in hoop stress (Braverman et al., 2005). Fig. 4 shows the increase in hoop stress due to reduction in wall thickness on the pipe.

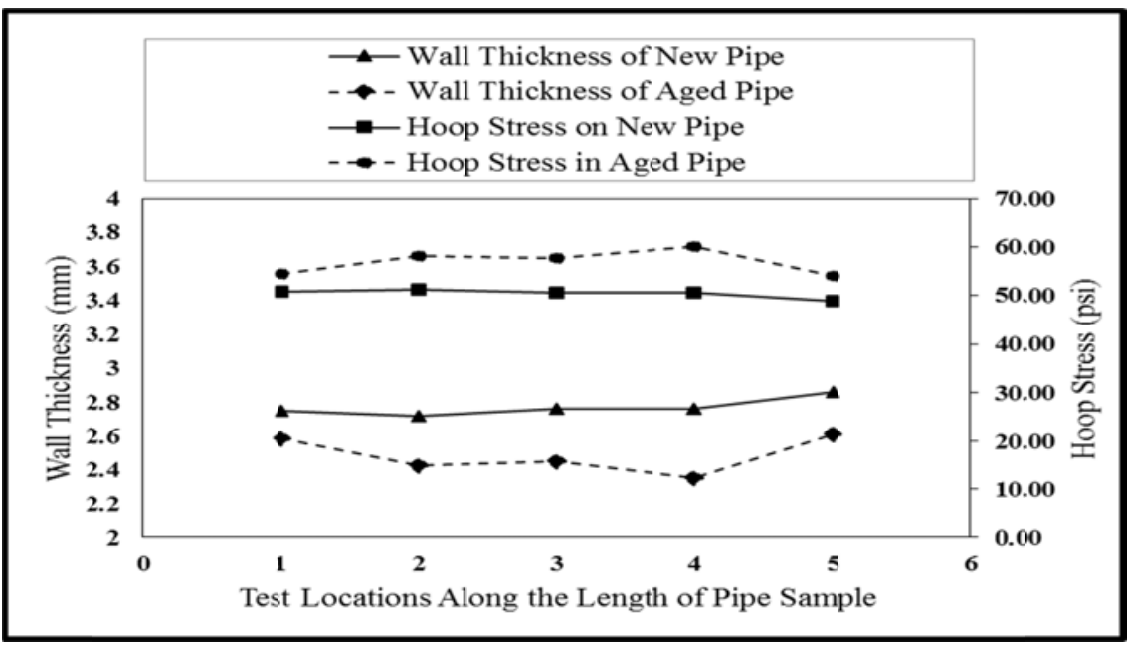

Fig. 4: Increase in hoop stress due to reduction in wall thickness

Microstructure of new carbon steel pipe exhibits bands of pearlite and ferrite, see Fig. 5. These bands are typical of the extruded material (Misiolek and Sikka, 2006). Inner surface layer of virgin pipe shows decarburized layer up to $0.1 \mathrm{~mm}$. This decarburized layer forms during cooling of steel to room temperature after hot extrusion (Callister and Rethwisch, 2007) this anisotropic structure shows poor resistance to impact load (Caballero et al., 2006). Abrasive action of steam removes the inner decarburized layer in aged carbon steel pipe. Prolong exposure to high temperature distributes pearlite uniformly throughout the matrix and no bands of pearlite and ferrite are observed in aged pipe, see Fig. 6. Mixture of ferrite and pearlite is more resistant to impact load. Amount of pearlite and ferrite, determined by image analyzing software ImageJ, was $40 \%$ and $60 \%$ respectively in new carbon steel, which changes to $25 \%$ pearlite and $75 \%$ ferrite due to twelve years of service in high 
temperature and pressure conditions. Reduction in pearlite occurs due to formation of graphite nodules, see Fig. 6 and Table 1. Decreasing amount of pearlite has deleterious effects as it decreases strength and hardness of steel (Gonzaga et al., 2009).

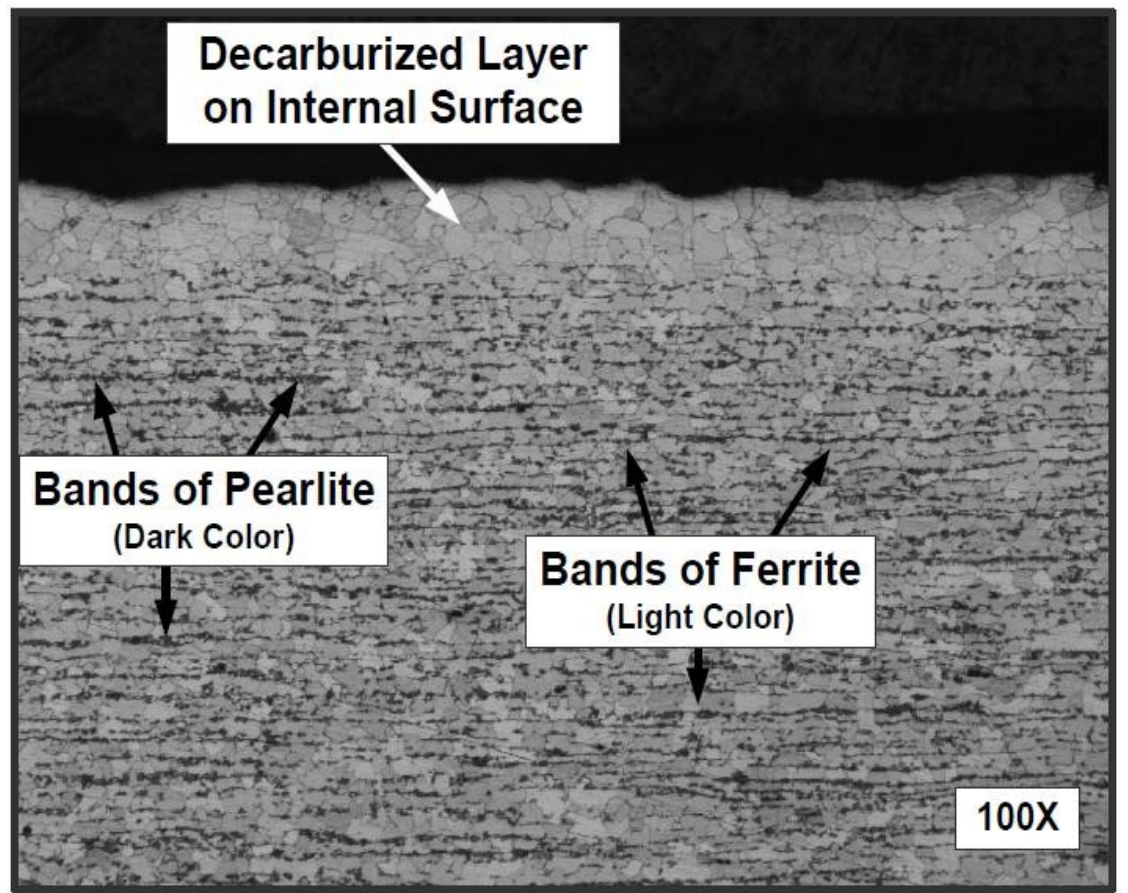

Fig. 5: Nital (1-10\% Nitric Acid in Ethanol) etched microstructure of new seamless SA 106B pipe at 100X

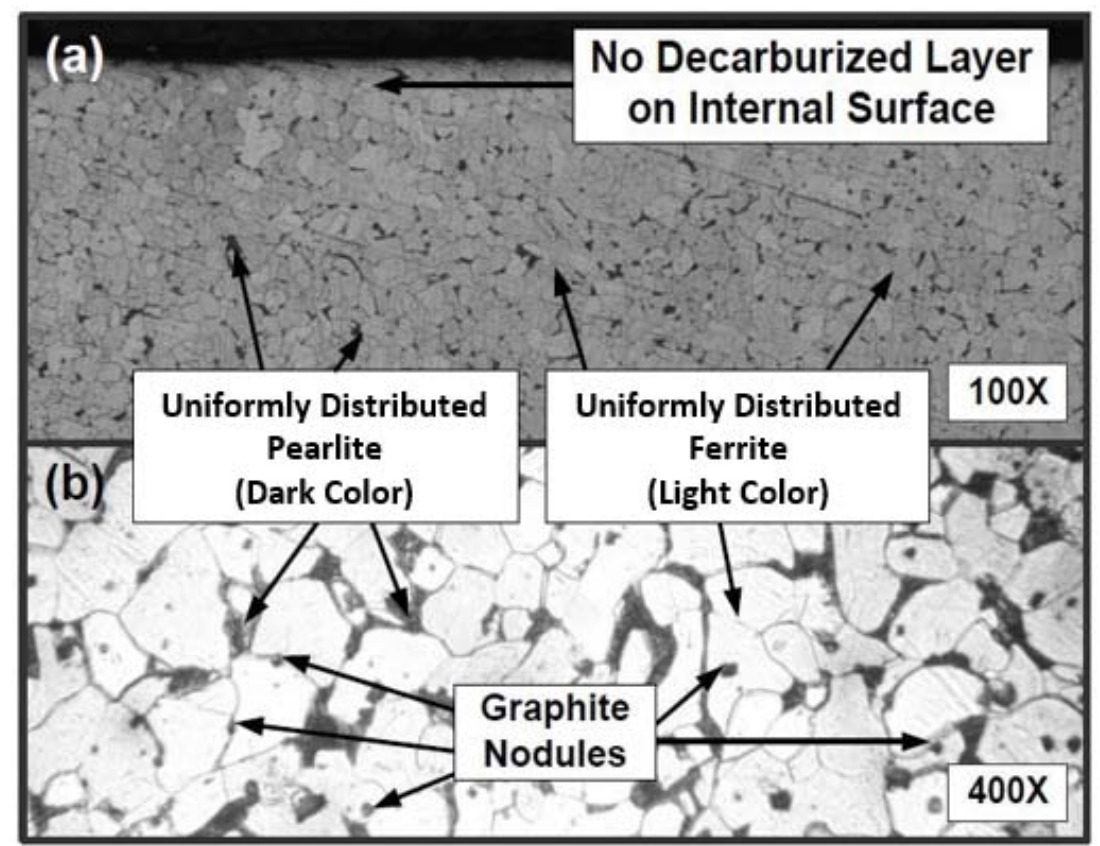

Fig. 6: Nital etched microstructure of aged seamless SA 106B pipe at (a) 100X and (b) 400X.

Table 1: Reduction in hardness due to ageing Rockwell Hardness Scale B (HRB)

\begin{tabular}{|c|c|c|c|}
\hline Pipe Surface & Virgin Pipe & Aged Pipe & Reduction (\%) \\
\hline Internal & 68.5 & 54.5 & 20 \\
\hline External & 64.5 & 64 & 0.7 \\
\hline
\end{tabular}

Hardness of the pipe samples was measured on internal and external surfaces. Reduction in hardness of internal pipe surface is observed $20 \%$. However, external surface experiences only $0.7 \%$ reduction in hardness. Reduction in hardness is 29 times more on internal layer of pipe material because this layer has been directly exposed to hot and pressurized steam.

\section{Conclusion}

Age related degradations have been observed in extraction steam piping of a nuclear power plant. Corrosion pits, which cause non-uniform reduction in thickness and reduce ultimate strength, have been observed with maximum depth of $0.07 \mathrm{~mm}$. $8.3 \%$ reduction in wall thickness has been observed due to mechanical rubbing and impinging of hot and 
pressurized steam on internal surface. The hoop stress, acting in radial direction has been increased due to reduced wall thickness. Initially present bands of pearlite and ferrite have been eliminated due to prolong exposure to high temperature which changes the mechanical properties. Microstructure of pipe material has been transformed into uniform mixture of pearlite and ferrite. Graphite nodules have also been formed by detachment of carbon from iron in pearlite, which has reduced pearlite content from $40 \%$ to $25 \%$. The reduction in pearlite is comparatively higher on internal surface layer of pipe as this layer faced hot and pressurized steam directly. The strength and hardness of the carbon steel SA $106 \mathrm{~B}$ has been reduced due to this microstructural transformation. The need to frequent examination has been revealed by this study as the combine effect of microstructural degradation and pitting on internal surface of the piping may lead to fracture.

\section{Acknowledgement}

The authors are thankful to Karachi Nuclear Power Plant (KANUPP) for providing samples and Peoples Steels Mills, Karachi, NED University of Engineering and Technology, Karachi and National Center for Non-Destructive Testing, Islamabad, for providing experimental facilities.

\section{References}

Bai G, Lu S, Li D and Li Y (2016). Influences of niobium and solution treatment temperature on pitting corrosion behaviour of stabilised austenitic stainless steels. Corrosion Science, 108: 111-124.

Braverman JI, DeGrassi G, Hofmayer C, MartinezGuridi G and Morante R (2005). Risk-Informed assessment of degraded buried piping systems in nuclear power plants. NUREG/CR-6876, BNLNUREG-74000-2005. Brookhaven National Laboratory, Washington DC, U.S. Nuclear Regulatory Commission, USA.

Caballero FG, García-Junceda A, Capdevila C and García de Andrés C (2006). Evolution of microstructural banding during the manufacturing process of dual phase steels. Materials transactions, 47(9): 2269-2276.

Callister WD and Rethwisch DG (2007). Materials science and engineering: an introduction. John Wiley and Sons, Inc., $7^{\text {th }}$ Edition, New York, USA: 7: 665-715

Deng B, Wang Z, Jiang Y, Wang H, Gao J and Li J (2009). Evaluation of localized corrosion in duplex stainless steel aged at $850 \mathrm{C}$ with critical pitting temperature measurement. Electrochimica Acta, 54(10): 2790-2794.
Furtado HC and May IL (2004). High temperature degradation in power plants and refineries. Materials Research, 7(1): 103-110.

Ginzel RK and Kanters WA (2002). Pipeline corrosion and cracking and the associated calibration considerations for same side sizing applications. NDT. net, 7(07): 1435-4934.

Gonzaga RA, Landa PM, Perez A and Villanueva P (2009). Mechanical properties dependency of the pearlite content of ductile irons. Journal of Achievements in Materials and Manufacturing Engineering, 33(2): 150-158.

Hänninen H (2009). Material development in new reactor designs-Gen III and SCWR concept. 20th international conference on structural mechanics in reactor technology (SMiRT), Dipoli Congress Centre, Espoo, Finland.

IAEA Nuclear Energy Series (2009). Integrity of reactor pressure vessels in nuclear power plants: Assessment of irradiation embrittlement effects in reactor pressure vessels steels. No. NP-T-3.11, IAEA Nuclear Energy Series, Vienna, Austria, http://www-

pub.iaea.org/MTCD/publications/PDF/Pub1382_ web.pdf.

Ivanova YP, Partalin TA and Tabakova BM (2012). Evaluation of Material Degradation in Steam Pipelines. $18^{\text {th }}$ World Conference on Nondestructive Testing, Durban, South Africa.

Mansoor M and Ejaz N (2009). Prediction of inservice microstructural degradation of A106 steel using eddy current technique. Materials Characterization, 60(12): 1591-1596.

Misiolek WZ and Sikka VK (2006). Physical and numerical analysis of extrusion process for production of bimetallic tubes (No. ORNL/TM2006/72). Lehigh University. Oak Ridge National Laboratory, U. S. Department of Energy, Tennessee, USA.

Ossai CI, Boswell B, and Davies I (2016). Markov chain modelling for time evolution of internal pitting corrosion distribution of oil and gas pipelines. Engineering Failure Analysis, 60: 209228.

Sidharth AAP (2009). Effect of pitting corrosion on ultimate strength and buckling strength of plate-a review. Digest Journal of Nanomaterials and Biostructures, 4(4): 783-788.

U.S.NRC (2009). License Renewal Application. Three mile island nuclear station unit 1 . Facility Operating License No. DPR-50. Availavble online at:

http://www.nrc.gov/reactors/operating/licensin g/renewal/applications/three-mile-island/tmilra.pdf.

Umer MA, Lee D, Waseem OA, Ryu HJ and Hong SH (2016). Fabrication of protective-coated SiC 
reinforced tungsten matrix composites with reduced reaction phases by spark plasma sintering. Metals and Materials International, 22(3): 493-500.

Waseem OA and Ryu HJ (2016). Tungsten-Based Composites for Nuclear Fusion Applications. In
AO Abdel Rahman and HE-D Mostafa Saleh (Eds.), Nuclear Material Performance. InTech, Available online http://www.intechopen.com/books/nuclearmaterial-performance/tungsten-basedcomposites-for-nuclear-fusion-applications. DOI: $10.5772 / 62434$. 